\title{
Expression of Diverse Neuropeptide Cotransmitters by Identified Motor Neurons in Aplysia
}

\author{
Paul J. Church and Philip E. Lloyd \\ Department of Pharmacological and Physiological Sciences and Committee on Neurobiology, University of Chicago, \\ Chicago, Illinois 60637
}

\begin{abstract}
Neuropeptide synthesis was determined for individual identified ventral-cluster neurons in the buccal ganglia of Aplysia. Each of these cells was shown to be a motor neuron that innervates buccal muscles that generate biting and swallowing movements during feeding. Individual neurons were identified by a battery of physiological criteria and stained with intracellular injection of a vital dye, and the ganglia were incubated in ${ }^{35} \mathrm{~S}$-methionine. Peptide synthesis was determined by measuring labeled peptides in extracts from individually dissected neuronal cell bodies analyzed by HPLC. Previously characterized peptides found to be synthesized included buccalin, FMRFamide, myomodulin, and the 2 small cardioactive peptides (SCPs). Each of these neuropeptides has been shown to modulate buccal muscle responses to motor neuron stimulation. Two other peptides were found to be synthesized in individual motor neurons. One peptide, which was consistently observed in neurons that also synthesized myomodulin, is likely to be the recently sequenced myomodulin $B$. The other peptide was observed in a subset of the neurons that synthesize FMRFamide. While identified motor neurons consistently synthesized the same peptide(s), neurons that innervate the same muscle often express different peptides. Neurons that synthesized the SCPs also contained SCP-like activity, as determined by snail heart bioassay. Our results indicate that every identified motor neuron synthesizes a subset of these methioninecontaining peptides, and that several neurons consistently synthesize peptides that are likely to be processed from multiple precursors.
\end{abstract}

Many neurons contain multiple transmitters. Often, 1 or more peptide cotransmitters are localized with a single conventional transmitter. We have chosen to study the role of peptide cotransmitters in a model system consisting of identified motor neurons in the buccal ganglia of Aplysia. These motor neurons generate the cyclic feeding motor output that drives biting and swallowing movements of muscles of the buccal mass (Gardner, 1971; Kupfermann, 1974). Previous results indicate that at least 5 methionine-containing peptides are synthesized in buccal ganglia and transported to buccal musclc (Lloyd, 1988). These pep-

\footnotetext{
Received July 9, 1990; revised Oct. 11, 1990; accepted Oct. 17, 1990.

We thank J. D. Hall and M. D. Whim for critical reading of the manuscript and C. White-Morris for expert technical assistance. This work was supported by NINCDS NS 23569 and by Brain Research Foundation grants.

Correspondence should be addressed to Philip E. Lloyd, Department of Pharmacological and Physiological Sciences, University of Chicago, 947 East 58th Street, Chicago, IL 60637.

Copyright (C) 1991 Society for Neuroscience 0270-6474/91/110618-08\$03.00/0
}

tides were identified as myomodulin (Cropper et al., 1987b), the 2 small cardioactive peptides $\left(\mathrm{SCP}_{\mathrm{A}}\right.$, Lloyd et al., 1987a; $\mathrm{SCP}_{\mathrm{R}}$, Morris et al., 1982), FMRFamide (Price and Greenberg. 1977), and buccalin (Cropper et al., 1988). Peptides synthesized in buccal ganglia are not transported uniformly to individual buccal muscles. Different muscle groups received different complements of peptides, and the peptides are transported in different amounts in particular nerves (Lloyd, 1988). Each of the 5 peptides has been shown to modulate the efficacy of motor neurons in producing buccal muscle contractions. However, both the nature and the underlying mechanism of the modulation vary for different buccal muscles. For example, in intrinsic muscle 5 (I5; also termed the accessory radula closer muscle), the SCPs enhance, while FMRFamide decreases, the amplitude of contractions produced by stimulation of motor neurons (Lloyd et al., 1984; Weiss et al., 1986). However, the SCPs and FMRFamide both enhance contractions of an extrinsic buccal muscle (Richmond et al., 1986), and the SCPs have been shown to enhance contractions of another intrinsic muscle, but by a different mechanism than in I5 (Lotshaw and Lloyd, 1990).

The observation that the peptides mentioned above are selectively synthesized in individual neurons, are selectively transported to individual buccal muscles, and are each capable of modulating motor-neuron-evoked contractions strongly suggests that they function as modulatory transmitters in buccal muscle. The evidence that the SCPs serve such a role is particularly strong. The SCPs are located in dense-core vesicles in varicosities in the CNS and buccal muscle and are released from identified neurons in culture in a stimulation- and calcium-dependent manner (Kreiner et al., 1986; Lloyd et al., 1986; Cropper et al., 1988; Reed et al., 1988). Cholinergic motor neuron B15 synthesizes the SCPs and innervates the I5 muscle (Cohen et al., 1978; Cropper et al., 1987a). Two independent procedures have been used to demonstrate release of the SCPs from B15 terminals in I5 muscle (Whim and Lloyd, 1989). Release of SCPs occurs only when B15 is stimulated at a relatively high frequency with a long burst duration. Because $\mathrm{B} 15$ can produce cholinergically mediated contractions with stimulation parameters that would not cause measurable release of the SCPs, it appears that $\mathrm{B} 15$ can function in 2 states: as a predominantly cholinergic neuron or as a combined cholinergic/peptidergic neuron. Similar results describing the release of the SCPs from B15 terminals in 15 muscle during stimulation of B15 in a pattern similar to that observed during feeding have recently been reported by Cropper et al. (1990). Finally, SCPs released from B1 5 terminals have been shown to modulate contractions evoked by stimulation of a second cholinergic motor neuron that innervates the I5 muscle (B16; Whim and Lloyd, 1990). Thus, 
the release of peptide cotransmitters from B 15 has physiological consequences.

The present study describes a series of experiments designed to identify individual motor neurons in the buccal ganglia and to determine the nature and relative quantity of peptide cotransmitters synthesized in them. These results provide a framework for physiological experiments designed to reveal the functional roles of these peptides.

\section{Materials and Methods}

Animals. Aplysia californica $(100-220 \mathrm{gm})$ were obtained from Marinus Inc. (Long Beach, CA), maintained in circulating artificial sea water (ASW) at $16^{\circ} \mathrm{C}$, and fed dried seaweed every $3 \mathrm{~d}$.

Identification of buccal motor neurons. Animals were immobilized with an injection of isotonic $\mathrm{MgCl}_{2}$. The dissection was carried out in a high- $\mathrm{Mg}^{2+}(110 \mathrm{~mm})$, low-Ca $\mathrm{Ca}^{2+}(2 \mathrm{~mm}) \mathrm{ASW}$ and was similar to that previously described (Whim and Lloyd, 1989). In brief, the buccal mass/ buccal ganglia complex was removed from animals, and all nerves were severed except buccal nerves 2 and 3 or, in some preparations, the radula nerve (nerve designations from Gardner, 1971). None of the neurons identified in this study had major axons projecting out buccal nerve 1 . The ganglia were pinned to a small Sylgard platform and desheathed, and the preparation was superfused with normal ASW for 1$2 \mathrm{hr}$. Motor neurons were identified by their position, size, nature of synaptic input from neurons B4 or B5 (Gardner, 1971), and ability to produce contractions in particular muscles when stimulated with intracellular current injections (Table 1). In some experiments, compound excitatory junction potentials (EJPs) were recorded from muscles using a suction electrode and a Grass P15D AC amplifier. Similar procedures were used to record action potentials in nerves following intracellularly driven action potentials in identified neuronal somata. This permits the identification of the primary axonal projections of the neuron. Buccal muscle nomenclature was taken from Howells (1942). In addition, we include a newly described pair of muscles (17s), which are medial to the 15 muscles and project from the base of $I 6$ to the connective tissue covering the radular sac. In all neuromuscular experiments, the ganglia were selectively superfused with high- $\mathrm{Mg}^{2+}$, low- $\mathrm{Ca}^{2+}$ solution by means of a small tube placed immediately adjacent to the ganglia, while the remainder of the bath containing the buccal muscles was superfused with normal ASW.

Peptide synthesis in identified neurons. Characterized neurons were electrophoretically injected with a vital stain ( $1 \%$ fast green) via an intracellular electrode for later identification. Control experiments comparing stained and unstained neurons indicated that fast green had no effect on peptide synthesis. Isolated desheathed ganglia were repinned in a small dish, and newly synthesized peptides were labeled with ${ }^{35} \mathrm{~S}$ methionine by incubation in a $0.5-\mathrm{ml}$ solution of $50 \%$ Aplysia hemolymph, 50\% ASW containing $1 \mathrm{~mm}$ colchicine, $25 \mathrm{U} / \mathrm{ml}$ penicillin, 25 $\mu \mathrm{g} / \mathrm{ml}$ streptomycin, $0.1 \% 2$-mercaptoethanol, and $1 \mathrm{mCi} / \mathrm{ml}{ }^{35} \mathrm{~S}$-methionine (Amersham; stabilized with pyridine 3,4-dicarboxylic acid) for $20 \mathrm{hr}$ at $16^{\circ} \mathrm{C}$, followed by a 4 -hr chase in ASW containing colchicine, antibiotics, mcrcaptocthanol (as above), and $1 \mathrm{~mm}$ cold methionine. In some experiments, the colchicine that was added to inhibit axonal transport of the peptides (Lloyd, 1988) was omitted from both label and chase solutions. Results from these experiments did not differ qualitatively or quantitatively from experiments conducted in the presence of colchicine. Only results from experiments with colchicine are presented in this study. Individual neuronal cell bodies were dissected using the freeze substitution method (Ono and McCaman, 1980), and single identified neurons were transferred to microtubes containing $50 \mu 10.02 \mathrm{M}$ trifluoroacetic acid (TFA) and $1 \mathrm{nmol}$ each of synthetic buccalin (American Peptide Co.), FMRFamide (Bachem), pedal peptide (Applied Biosystems), myomodulin, $\mathrm{SCP}_{\mathrm{A},}$ and $\mathrm{SCP}_{\mathrm{B}}$ (Peninsula). Tubes were heated at $100^{\circ} \mathrm{C}$ for $10 \mathrm{~min}$, and the samples were cooled and filtered through $0.45-\mu \mathrm{m}$ Acro LC1 3 filters (Gelman). Samples were analyzed by reversephasc HPLC on a Brownlee RP-300 C8 column. The initial separation used a 3-part gradient, from $25 \%$ to $29 \% \mathrm{CH}_{3} \mathrm{CN}$ in 2 min, from $29 \%$ to $35 \% \mathrm{CH}_{3} \mathrm{CN}$ in $12 \mathrm{~min}$, and from $35 \%$ to $45 \% \mathrm{CH}_{3} \mathrm{CN}$ in $6 \mathrm{~min}$, at a flow rate of $2 \mathrm{ml} / \mathrm{min}$. Both aqueous and $\mathrm{CH}_{3} \mathrm{CN}$ solutions contained $0.01 \mathrm{M}$ heptafluorobutyric acid (HFBA). This gradient effectively resolved each of the synthetic peptides from each other (Fig. 1). Fractions were collected at 0.4-min intervals, aliquoted, and liquid scintillation counted. Some fractions were also subsequently analyzed using a second
Table 1. Physiological characteristies and peptide synthesis of identified neurons in the buccal ganglia of Aplysia

\begin{tabular}{|c|c|c|c|c|}
\hline Neuron & $\begin{array}{l}\text { Muscles } \\
\text { innervated }\end{array}$ & $\begin{array}{l}\text { Projection of } \\
\text { major axons }^{b}\end{array}$ & $\begin{array}{l}\text { Peptide } \\
\text { synthesis }\end{array}$ & $\begin{array}{l}\text { SCP } \\
\text { content }^{d}\end{array}$ \\
\hline B3 & $\mathrm{i} I 3_{\mathrm{m}, \mathrm{a}}$ & i N2 & $\mathrm{Fa}$ & $<10$ \\
\hline B4 & i I7 & i N3 & $\mathrm{Fa}$ & $<10$ \\
\hline B5 & i I7 & i N3 & $\mathrm{Fa}$ & $<10$ \\
\hline B6 & $\mathrm{i}, \mathrm{c} \mathrm{I} 3_{\mathrm{p}, \mathrm{m}}, \mathrm{I} 6$ & $\mathrm{i}, \mathrm{c} \mathrm{N} 2, \mathrm{~N} 3$ & SCPs & $115 \pm 57$ \\
\hline B7 & i I6 & i N3 & $\mathrm{Fa}, \mathrm{Mm}, \mathrm{SCPs}$ & $58 \pm 24$ \\
\hline B8a & i, c 14, I6 & Radular N & $\mathrm{Mm}$ & $<10$ \\
\hline $\mathrm{B} 8 \mathrm{~b}$ & $\mathrm{i}, \mathrm{c}$ I4, I6 & Radular N & $\mathrm{Mm}$ & $<10$ \\
\hline B9 & $\mathrm{i}, \mathrm{c} \mathrm{I} 3_{\mathrm{p}, \mathrm{m}}, \mathrm{I} 6$ & $\mathrm{i}, \mathrm{c} \mathrm{N} 2, \mathrm{~N} 3$ & SCPs & $185 \pm 44$ \\
\hline $\mathrm{B} 10$ & $\mathrm{i}, \mathrm{c} \mathrm{I} 3_{\mathrm{p}, \mathrm{m}}$ & $\mathrm{i}, \mathrm{c}$ N2 & SCPs & $207 \pm 88$ \\
\hline B1 1 & i I6 & i N3 & $\mathrm{Mm}, \mathrm{SCPs}$ & $223 \pm 55$ \\
\hline B15 & i I5 & i N3 & $\mathrm{Bn}, \mathrm{SCPs}$ & $60 \pm 8$ \\
\hline B16 & i 15 & i N3 & $\mathrm{Bn}, \mathrm{Mm}$ & $<10$ \\
\hline B38 & $\mathrm{i} I 3_{\mathrm{a}}$ & i N2 & SCPs & $171 \pm 28$ \\
\hline B39 & $\mathrm{i}, \mathrm{c} \mathrm{I} 3_{\mathrm{a}}$ & i N2 & $\mathrm{Fa}$ & $<10$ \\
\hline B43 & i Il & i N2 & SCPs & $62 \pm 19$ \\
\hline B44 & i, c I6 & $\mathrm{i}, \mathrm{c}$ N3 & $\mathrm{Mm}$ & $<10$ \\
\hline B45 & i II & i N3 & $\mathrm{Mm}$ & $<10$ \\
\hline
\end{tabular}

${ }^{a}$ Indicates muscle regions that contracted in response to relatively low-frequency firing of each motor neuron. In addition, multiaction neurons B4 and B5 provide inhibitory or mixed excitatory/inhibitory junction potentials that did not elicit contractions in the I3 muscle (also see Nagahama and Takata, 1990). i, ipsilateral; $c$, contralateral. The large 13 muscle is divided into anterior (a), middle (m), and posterior (p) segments.

${ }^{n}$ Nerve designations from Gardner (1971).

Bn, buccalin; Fa, FMRFamide; Mm, myomodulin.

${ }^{d}$ Fmol total $\mathrm{SCP}_{\mathrm{A}}$ - and $\mathrm{SCP}_{\mathrm{B}}$-like bioactivity. Values are mean $\pm \mathrm{SEM}$ with each neuron taken from a minimum of 4 preparations. Threshold sensitivity was about $10 \mathrm{fmol} /$ neuron extract.

gradient. Aliquots from the radioactive peaks of interest were pooled, dried, and run on a linear gradient from $5 \%$ to $54 \% \mathrm{CH}_{3} \mathrm{CN}$ in $20 \mathrm{~min}$ at $2 \mathrm{ml} / \mathrm{min}$. In these runs, the aqueous and $\mathrm{CH}_{3} \mathrm{CN}$ solutions contained $0.01 \mathrm{M}$ TFA. Fractions of 0.4 or $0.2 \mathrm{~min}$ were counted. Elution profiles of the synthetic peptides were determined from absorbance at $215 \mathrm{~nm}$. In total, 136 ncurons wcrc analyzed from 25 buccal ganglia preparations.

Measurement of SCPs in identified neurons. Characterized neurons were stained with fast green, dissected, and extracted as described above, except the TFA solution contained $0.5 \mathrm{nmol}$ [Tyr $\left.{ }^{\hat{s}}\right]$ substance $\mathrm{P}(\mathrm{Ba}$ chem) and no other peptides. $\left[\mathrm{Tyr}^{8}\right]$ substance $\mathrm{P}$ acts as an effective carrier for the SCPs (Whim and Lloyd, 1989). Extracts were dried, and the SCP-like activity present in them was measured using the isolated snail heart bioassay. This bioassay has been described previously (Lloyd, 1978) and was used because it is sufficiently sensitive to measure SCPs from single neurons and, over a small range, the increase in amplitude of spontaneous heart beats is linearly proportional to the amount of the SCPs in the injection (Lloyd, 1986). Hearts were calibrated before and after test samples with injections of SCPs $(5,10$, and $20 \mathrm{fmol}$ each of an equimolar mixture of $\mathrm{SCP}_{\mathrm{A}}$ and $\mathrm{SCP}_{\mathrm{B}}$ ). Control experiments using amounts of synthetic SCPs similar to that found in cell extracts indicated that there was a $\sim 75 \%$ recovery of bioactivity down to the level of 10 $20 \mathrm{fmol}$. [Tyr ${ }^{8}$ ] substance $P$ was nearly completely inactive in the assay. The ratios of the activity of either of the SCPs to the activity of other substances on the heart were as follows: buccalin, $>10^{4}$; FMRFamide, $3354 \pm 1065$; myomodulin, $7619 \pm 4622$; and serotonin, $3.3 \pm 1.3$ ( $\pm \mathrm{SD} ; N=4$ or 5 heart preparations). Thus, only serotonin had significant activity on the heart assay. In total, 92 neurons were analyzed from 12 buccal ganglia preparations.

\section{Results}

\section{Identification of ventral-cluster motor neurons}

Most of the larger motor neurons ( $\geq 60 \mu \mathrm{m}$ diameter) in the ventral cluster can be identified unequivocally by a combination of their size, position (Fig. 2), and several physiological criteria. 


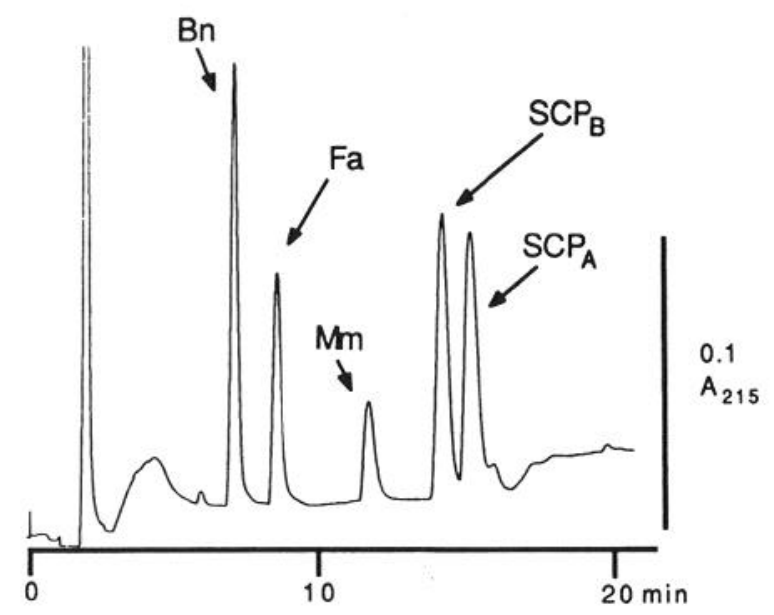

Figure 1. Absorbance profiles of 5 methionine-containing peptides synthesized in ventral-cluster motor neurons. A mixture consisting of $10 \mathrm{nmol}$ of each synthetic peptide was run on HPLC with HFBA as a counterion. Absorbance peaks associated with each peptide are indicated by arrows. Absorbance of peptides varies as a result of different amino acid compositions. Slow shifts in absorbance baseline were always observed when HFBA was used as the counterion. Peptides: buccalin $(B n)$, FMRFamide $(F a)$, myomodulin $(\mathrm{Mm}), S C P_{A}$, and $S C P_{B}$.

Most ventral-cluster motor neurons receive similar inhibitory synaptic input from neurons B4 and B5, which have both interneuronal and motor functions. However, input from B4/B5 was useful in identifying 2 neurons. B7 receives biphasic excitatory/inhibitory synaptic input, while B38 was the only ventralcluster neuron we have studied that never received synaptic input from B4/B5 (Gardner and Kandel, 1977; Lotshaw and Lloyd, 1990). The most useful of the physiological criteria was the location of the muscle fibers innervated by the neuron. Usually, this was determined by the location of contractions produced by intracellular stimulation of a neuron. The location of fibers innervated by each of the identified neurons was confirmed by demonstrating that extracellularly recorded EJPs followed intracellular action potentials with fixed latencies at frequencies of at least 10 spikes/sec. In these experiments, the ganglia were selectively superfused with low- $\mathrm{Ca}^{2+}$ ASW to inhibit central synaptic transmission. Neurons were numbered based loosely on the neuronal maps of Gardner (1971), with the addition of B38 (Lotshaw and Lloyd, 1990) and 5 newly identified neurons (B8b, B39, B43, B44, and B45). In 2 cases, the only criterion that could be used to differentiate between adjacent neurons was their position relative to each other within a ganglion. Because this appeared to us to be the weakest of the criteria, these identifications must be considered tentative. We indicate the inability to unequivocally identify a neuron as an individual by a letter following the neuron designation number (B8a and B8b). In addition, the previously identified B4 and B5 can only be distinguished by their relative positions and should also be included in this category (Gardner and Kandel, 1977; Rosen et al., 1982). Table 1 summarizes the characteristics of the 17 identified ventral-cluster motor neurons that were analyzed for peptide synthesis in the present study.

\section{Peptide synthesis in identified motor neurons}

Incubating ganglia with radiolabeled amino acids followed by running extracts of the neuronal cell bodies on HPLC permits identification of multiple peptides synthesized by a neuron and
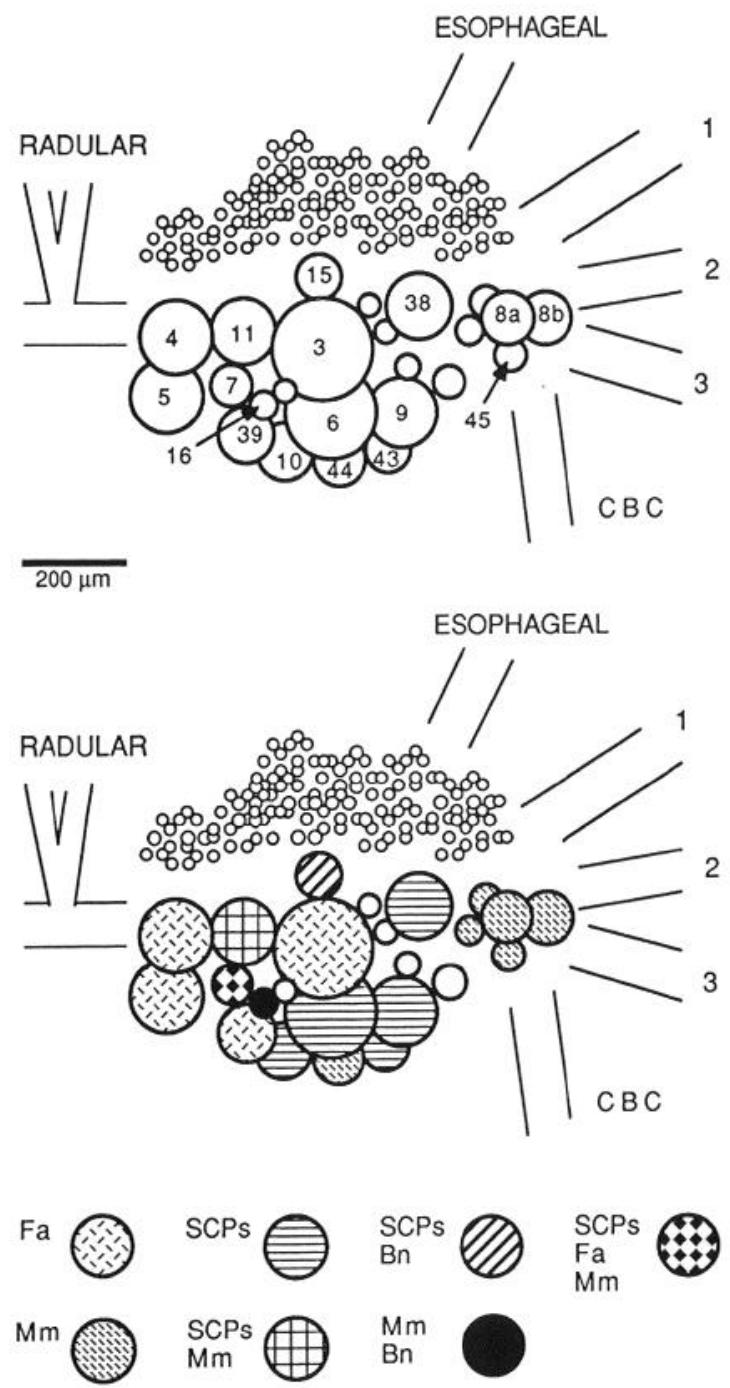

Figure 2. Diagrams of the rostral surface of a buccal ganglion and location of identified ventral-cluster motor neurons. The top diagram indicates position and relative size of neurons in the cluster. Criteria used to identify neurons are given in Table 1 . The bottom diagram indicates patterns of peptide synthesis observed in identified neurons. $C B C$, cerebral-buccal connective. Nerve designations are as in Gardner (1971). Peptides: buccalin $(\mathrm{Bn})$, FMRFamide $(\mathrm{Fa})$, myomodulin $(\mathrm{Mm})$ and SCPS.

also provides quantitative measurements of the rates of this synthesis. In addition, by running several modes of HPLC, the chemical identification of a labeled peptide(s) can be confirmed. Thus, this procedure provides major advantages over immunocytology. Neurons were identified as described above, injected with fast green, and incubated in ${ }^{35} \mathrm{~S}$-methionine. After incubation and chase periods, individual cell bodies were dissected from the ganglia, extracted, and run on HPLC with HFBA as a counterion. Overall, 7 patterns of synthesis of methioninecontaining peptides were observed in ventral-cluster neurons. Three of the patterns consisted of labeled peptides that may be processed from single precursors (Fig. 3). The most common pattern, consisting of the $2 \mathrm{SCPs}$, was found in $\mathrm{B} 6, \mathrm{~B} 9, \mathrm{~B} 10$, $\mathrm{B} 38$, and B43. A pattern consisting of FMRFamide (see below) was found in B3, B4, B5, and B39. A pattern consisting of myomodulin and a second, smaller peak was observed in B8a, $\mathrm{B} 8 \mathrm{~b}, \mathrm{~B} 44$, and B45. 


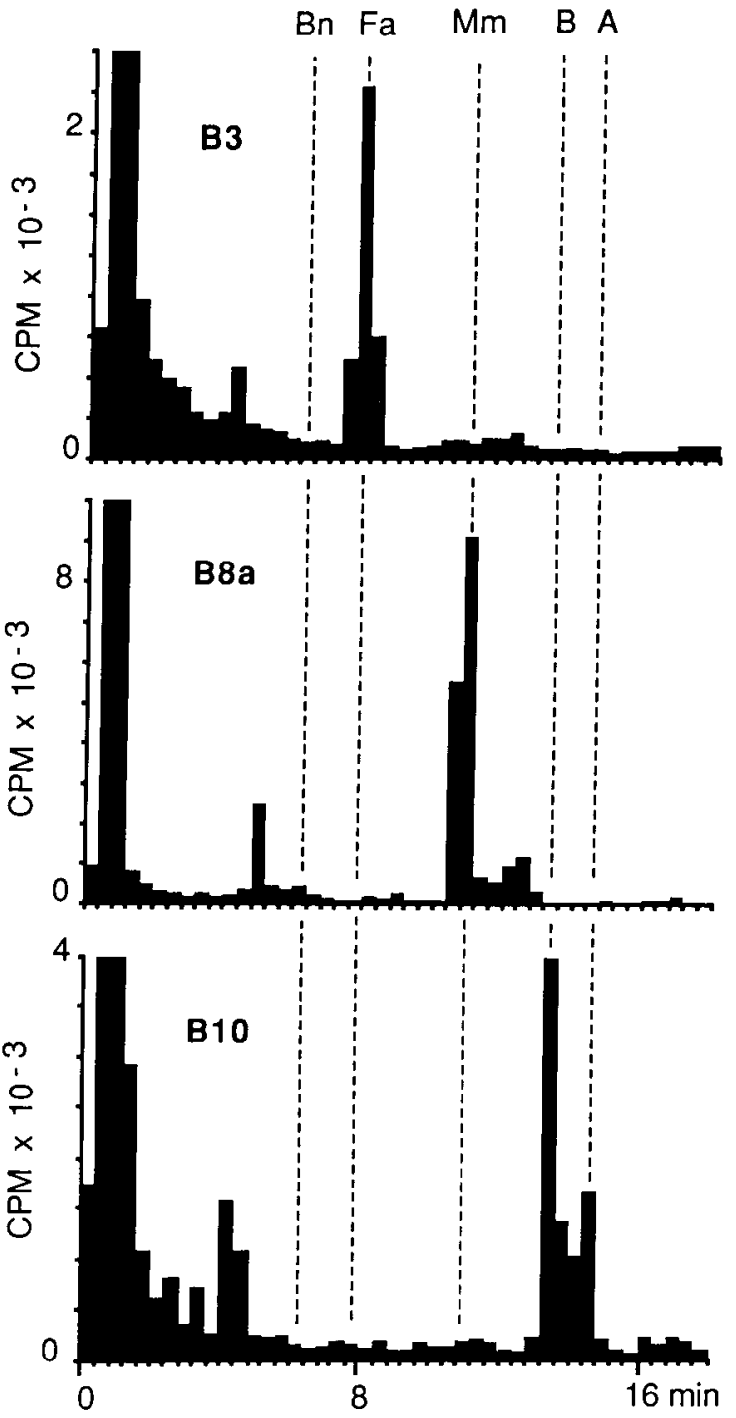

Figure 3. Examples of HPLC of extracts from neurons that synthesize peptides that may be processed from single precursors. Cell extracts were run with HFBA as a counterion (see Fig. 1). B3 is an example of a neuron that synthesizes primarily FMRFamide ( $\mathrm{Fa}$; see Fig. 5). $\mathrm{B} 8 \mathrm{a}$ is an example of a neuron that synthesizes primarily myomodulin $(\mathrm{Mm})$ and a smaller peak with longer retention time that includes myomodulin b. $B 10$ is an example of a neuron that primarily synthesizes the SCPs $(A$ and $B$ ). Retention times of synthetic peptides are indicated by the dashed lines. In this and the following figure, unincorporated ${ }^{35} \mathrm{~S}-\mathrm{me}$ thionine is the predominant component of the large truncated peak with brief retention time $(0-3 \mathrm{~min})$. The peaks of radiolabel with a retention time about 2 min shorter than buccalin $(B n)$ were observed in extracts from every neuron (also see Fig. 4). The identity of this peak has not been determined. Peptide identities were confirmed by running aliquots from these peaks on HPLC with TFA as a counterion (e.g., Fig. 5).

Four patterns of labeled peptides were observed in which the peptides were likely to be products of multiple precursors (Fig. 4). One pattern, which was found in B11, consisted of the synthesis of myomodulin and the SCPs. The most complex pattern was observed in B7 and consisted of the synthesis of FMRFamide, myomodulin, and the SCPs (Fig. 4). We also confirmed that B 15 synthesized the SCPs and buccalin, and that B16 synthesized myomodulin and buccalin (Fig. 4; Cropper et al., 1987a, 1988; Kupfermann et al., 1988). Small peaks that coincided with myomodulin and FMRFamide were occasionally observed in $\mathrm{B} 15$, but these have not been further analyzed.
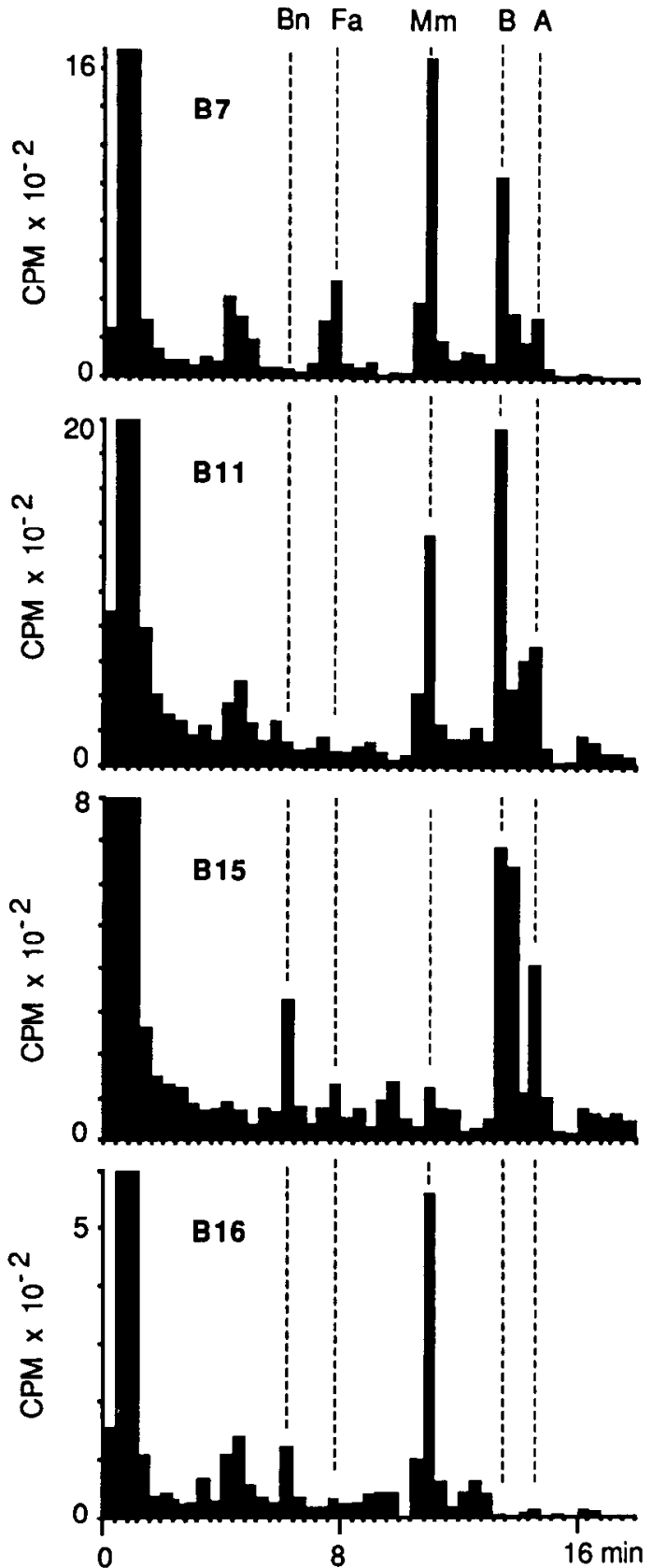

Figure 4. Examples of HPLC of extracts from neurons that synthesize peptides that are likely to be processed from multiple precursors. Cells were run with HFBA as a counterion (see Fig. 1). Retention times of synthetic peptides are indicated by the dashed lines. $B 7$ synthesizes FMRFamide $(F a)$, myomodulin $(M m)$, and the SCPs $(A$ and $B)$. BII synthesizes myomodulin and the SCPs. $B 15$ synthesizes buccalin $(B n)$ and the SCPs, while B16 synthesizes buccalin and myomodulin. Peptide identities were confirmed by running aliquots from the peaks on HPLC with TFA as a counterion (e.g., Fig. 5).

In the myomodulin pattern, the ratio of myomodulin to the smaller peak with a longer retention time was $5.27 \pm 0.98( \pm \mathrm{SD}$; $N=18$; range, 3.4-7.1). Neurons B8a, B8b, B16, B44, and B45 were used to generate this ratio, while myomodulin-synthesizing neurons $\mathrm{B} 7$ and $\mathrm{B} 11$ were not because the second peak was contaminated slightly by the onset of the $\mathrm{SCP}_{\mathrm{B}}$ peaks. This uniform ratio is consistent with the interpretation that the second peak is processed from the same precursor as myomodulin and is likely to include the recently sequenced myomodulin B 


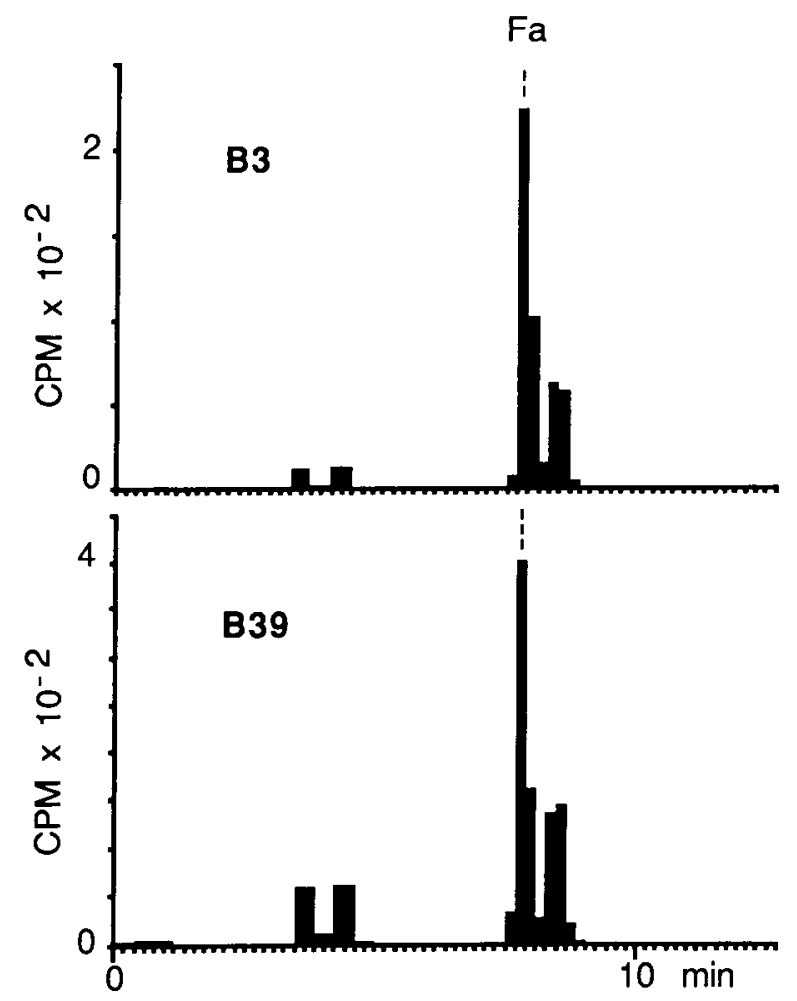

Figure 5. Aliquots from fractions that coeluted with synthetic FMRFamide $(F a)$ when run on HPLC with HFBA as a counterion were run with TFA as a counterion. The retention time of synthetic FMRFamide is indicated by a dashed line. For neurons $B 3$ and $B 39$, a major peak continucd to coclute with synthetic FMRFamide, while a second peak eluted with a longer retention time and 2 small peaks had shorter retention times than that of synthetic FMRFamide. because it was also found in $\mathrm{B} 16$, where it has been previously identified (Villim et al., 1989).

Aliquots from the labeled peaks for each identified neuron were also run on a second mode of HPLC with TFA as a counterion to confirm peptide identifications. The labeled SCPs, myomodulin, and buccalin peaks from the first mode of HPLC always continued to coelute precisely with the appropriate synthetic peptides in the sccond mode of HPLC. The pcaks in neurons B3 and B39 appeared to be broader than the absorbance peak produced by synthetic FMRFamide in the first mode of HPLC, and when aliquots of these peaks from B3 and B39 were run individually in the second mode of HPLC, they each resolved into 2 major and 2 minor labeled peaks (Fig. 5). The predominant peak had the same retention time as FMRFamide, while the second major peak had a longer retention time. These results are not likely to be due to chemical modification of FMRFamide because the synthetic peptide was treated in an identical fashion and did not produce the second peak. The ratio of the peaks in B3 and B39 varied considerably even for the same neuron from different preparations. The FMRFamide peak from other neurons (B4, B5, B7) produced a single peak with retention times identical to synthetic FMRFamide when run on the same gradient. Thus, it is possible that more than 1 precursor is being expressed in $\mathrm{B} 3$ and $\mathrm{B} 39$, though differences in precursor processing cannot be ruled out (e.g., Fisher et al., 1988).

A composite of the overall results for peptide synthesis in identified neurons is shown in Figure 6. The data in this figure are presented as incorporation into a peptide as a percentage of total radioactivity recovered from the HPLC run to compensate for the wide range in size of neuronal cell bodies (see Fig. 2). Although occasionally individual neurons or even all the ventral-cluster neurons in a particular ganglion did not show significant incorporation of labeled methionine into peptides, when

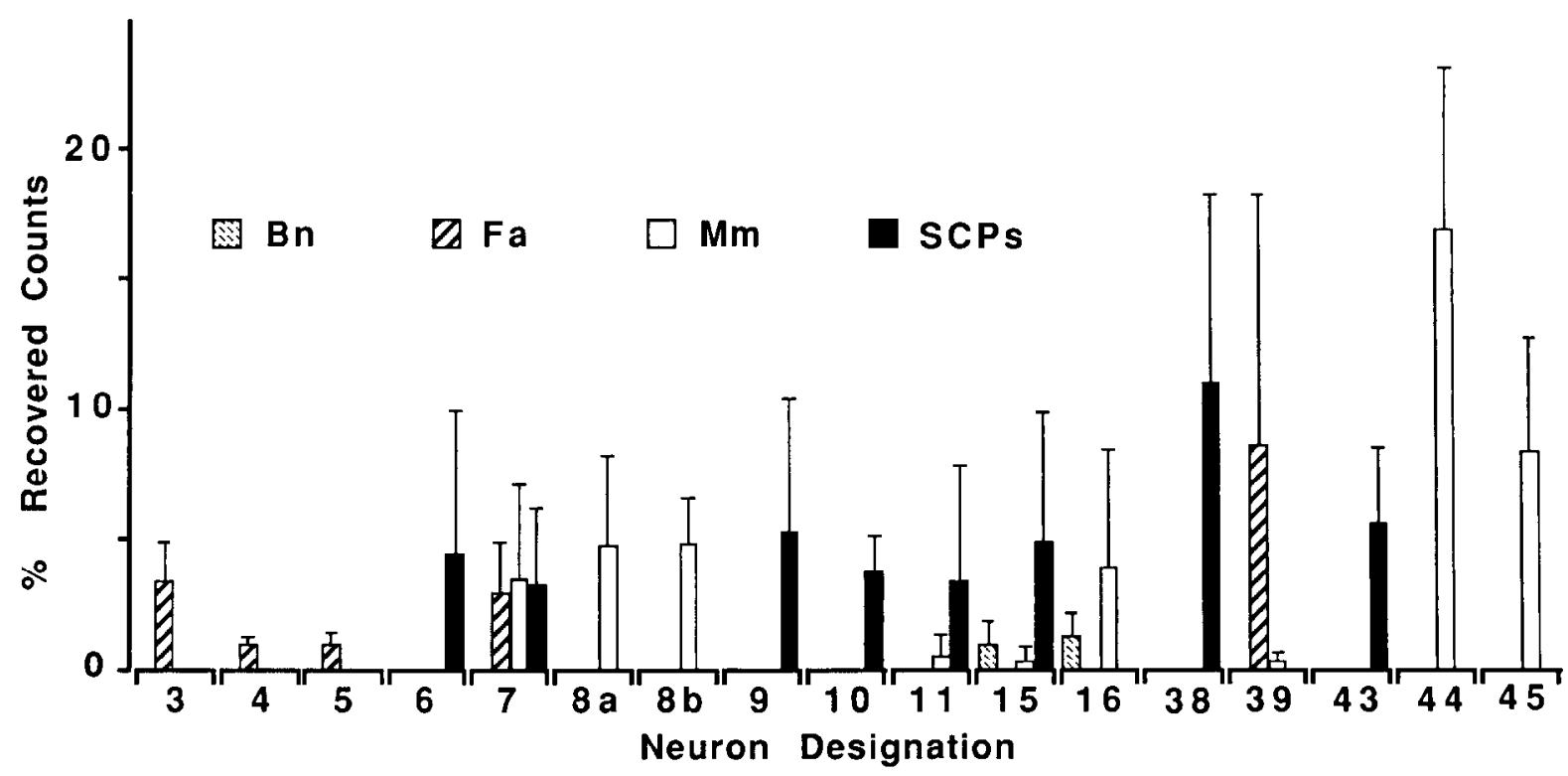

Figure 6. Peptide synthesis in identified ventral-cluster neurons. Incorporation into peptides is represented as the percentage of total radioactivity recovered from the HPLC run to compensate for the wide range of sizes of the neuronal cell bodies. In addition, the radioactivity associated with myomodulin or $\mathrm{SCP}_{\mathrm{B}}$ was divided by 2 because these peptides contain 2 methionine residues. Values are mean $\pm \mathrm{SD}$, with each neuron analyzed from a minimum of 3 preparations. Occasionally, B15 and B39 extracts contained small peaks of radioactivity that coeluted with synthetic myomodulin. These peaks contained insufficient radioactivity to confirm peptide identity on a second HPLC gradient. Peptides: buccalin ( $B n)$, FMRFamide $(\mathrm{Fa})$, myomodulin $(\mathrm{Mm})$, and $S C P S$. 
incorporation did occur, particular identified neurons synthesized the same peptide(s). Of the 17 neurons studied, 8 synthesized the SCPs, 8 synthesized myomodulin, and 5 synthesized FMRFamide. In addition, 3 small, unidentified neurons in the B8 cluster also synthesized myomodulin. Only the 2 neurons (B15 and B16) that innervate the 15 muscle synthesized measurable quantities of buccalin. Finally, neurons with indistinguishable physiological properties (B4 and B5, B8a and B8b) synthesized very similar levels of the same peptides (Fig. 6).

\section{Measurement of the SCP content of identified motor neurons}

In order to estimate how the rates of synthesis compared to peptide content in the ventral-cluster neurons, we took advantage of the sensitive snail heart bioassay to measure the amounts of cardioactive substances in extracts from identificd ncurons. Buccalin, FMRFamide, and myomodulin are each at least 1000fold less potent than the SCPs in the bioassay (see Materials and Methods). Serotonin is only about 3-fold less active, but no serotonergic neurons are located in the buccal ganglia, and the amounts of serotonin present in terminals on neuronal somata are too low to be measured in this assay (Schwartz and Shkolnik, 1981; Ono and McCaman, 1984). Table I summarizes the values obtained for the SCP content of identified ventralcluster neurons. Only those neurons that were found to synthesize the SCPs contained measureable cardioactive substances. This independently confirms the specificity of the ${ }^{35} \mathrm{~S}$-methionine-labeling procedure. In general, identified neurons that synthesized the most labeled SCPs also contained the largest amounts of the SCPs, though this relationship was not invariant, because B38 contained less of the SCPs than would have been predicted from the labeling studies. Thus, for the SCPs, the observed rates of synthesis reflect the presence of about 50-250 fmol of $\mathrm{SCP}_{\mathrm{A}}$ and $\mathrm{SCP}_{\mathrm{B}}$ per neuronal somata.

\section{Discussion}

Every motor neuron in the ventral cluster analyzed in our study synthesized methionine-containing peptide cotransmitter(s). Where previous studies had localized peptides to identified neurons, our studies confirmed synthesis of those peptides (Cropper et al., 1987a, 1988; Kupfermann et al., 1988; Church et al., 1991). Although there was some variability in our quantitative measurements of peptide synthesis, it appears that the particular peptides expressed in a given neuron were consistent from animal to animal.

Ihe expression of methionine-labeled peptides may also reflect the presence of other peptides that do not contain methionine residucs and are processed from the same precursor. For example, a cDNA that encodes buccalin may also encode an additional 9 related peptides, including buccalins $B$ and $C$, which have recently been sequenced (Weiss et al., 1988; Miller et al., 1989). These buccalins do not contain methionine and have been localized to motor neurons B15 and B16. The SCPs' precursor encodes single copies of $\mathrm{SCP}_{\mathrm{A}}$ and $\mathrm{SCP}_{\mathrm{B}}$ and also contains addition potential cleavage sites (Mahon et al., 1985). The FMRFamide precursor encodes for multiple copies of FMRFamide but also contains additional regions that may be processed into peptides with no sequence similarity to FMRFamide (Taussig and Scheller, 1986). However, labeling using a single amino acid has the advantage of keeping the number of labeled peptides at a manageable level. Even with this advantage, it was necessary to develop special HPLC gradients to resolve all the peptides observed in this study.
The motor neuron found to have the most complex synthesis pattern in the present study was B7, which expresses the FMRFamide, myomodulin, and SCP patterns of synthesis. There is reason to believe that even this is an underestimate of its complexity because $\mathrm{B} 7$ has also been shown to be immunoreactive with antisera directed towards the shared carboxyl terminals of gastrin and cholecystokinin (CCK; Ono, 1986). Of the peptides we have observed to be synthesized in B7, only FMRFamide (Phe-Met-Arg-Phe-amide) shows sequence similarity to the carboxyl terminals of gastrin and CCK (-Trp-MetAsp-Phe-amide). However, the gastrin/CCK-directed antisera do not cross-react with FMRFamide because other known FMRFamide-containing neurons do not stain with these antisera. Although it has been shown that the immunoreactivity in B7 is not associated with authentic gastrin or CCK (Ono, 1986), these results do suggest, as discussed earlier, that it is likely that the ventral-cluster motor neurons contain other as yet uncharacterized peptides.

The physiological and behavioral implications of the expression of such a variety of neuropeptides in buccal motor neurons must await detailed physiological studies such as those carried out for the SCPs in B15 (Whim and Lloyd, 1989, 1990; Cropper et al., 1990). However, several generalizations can be drawn from our results: Neurons that innervate the same muscle fibers often synthesize different peptides. This observation is consistent with earlier results from studies of peptides synthesized by motor neurons innervating muscle 15 (Cropper et al., 1987a, 1988). Our present findings are also consistent with previous results from experiments in which peptides synthesized in the buccal ganglia and transported to buccal muscles were examined (Lloyd, 1988). One of the major observations was that myomodulin was transported in large amounts to muscles 14 and I6 primarily via the radular nerves. In the present study, both identified motor neurons, which innervate $\mathrm{I} 4$ and $\mathrm{I} 6$ via the radular nerve, synthesize myomodulin. In addition, in the transport study, only the relatively small 15 muscle received amounts of labeled buccalin comparable to the other peptides and received essentially no FMRFamide. In our present study, the I5 motor neurons (B15 and B16) synthesized no FMRFamide and were the only neurons found to synthesize significant quantities of buccalin. The similarities in the results from these 2 studies raise the possibility that a significant amount of the peptides transported to buccal muscles may be synthesized in the motor neurons themselves. However, at least some of the peptides found to be transported to muscle from buccal ganglia are likely to be from neurons other than those in the ventral cluster. For example, previous results indicate that a number of small neurons that have peripheral axons and are thought to be sensory neurons (Fiore and Geppetti, 1980) also synthesize FMRFamide (Lloyd et al., 1987b). In addition, another group of small neurons with peripheral axons contains SCP-like immunoreactivity (Lloyd et al., 1985; Miller et al., 1988).

Neurons in the buccal ganglia that express a particular peptide show a modcrate degrec of organization. The csophagcal cluster is the predominant cluster of neurons that synthesize peptides. All neurons in this cluster, which includes neurons B1 and B2, synthesize the SCPs (Lloyd et al., 1985). B1 and B2 send their axons out the esophageal nerve and have been shown to regulate gut motility during feeding (Lloyd et al., 1988). In the present study, we have identified another discrete cluster of about 5 medium-sized neurons, including B8a, B8b, and B45, that synthesizes myomodulin and another peptide likely to be myomod- 
ulin B. There are also 2 clusters of more loosely associated neurons. One consists of 4 medial large neurons that synthesize FMRFamide, while a second, loose cluster consists of 5 large neurons that synthesize the SCPs (Fig. 2). It would be interesting to determine if these associations of neurons expressing the same peptide transmitters have a functional or developmental explanation.

Coexistence of modulatory neuropeptides with conventional transmitters has been reported previously in invertebrates (Bishop et al., 1984; Schwarz et al., 1984; Kuhlman et al., 1985; O'Shea and Schaffer, 1985), as well as in vertebrates (Gibson et al., 1984; Ch'ng et al., 1985; New and Mudge, 1986). Furthermore, in a number of instances, there is evidence that these neuropeptides may modulate several aspects of neuromuscular transmission (Adams and O'Shea, 1983; New and Mudge, 1986; Bishop et al., 1987; Mulle et al., 1988; Calabrese, 1989). Thus, modulation by peptides released from motor neuron terminals may be phylogenetically widespread.

Although previous physiological studies with buccal motor neurons were directed specifically towards the SCPs in I5 muscle (Whim and Lloyd, 1989, 1990; Cropper et al., 1990), there is good reason to believe modulation by the SCPs and other peptides is widespread in other buccal muscles. First, the rates at which the SCPs, FMRFamide, and myomodulin are synthesized in buccal ganglia and transported to buccal muscles were roughly similar (Lloyd, 1988). Second, every buccal motor neuron analyzed in the present study contains and synthesizes modulatory peptides. Thus, modulation of buccal muscle contractions by peptide cotransmitters released from motor neurons may contribute significantly to the behavioral plasticity observed during feeding in Aplysia (Susswein et al., 1978).

The present study has identified motor neurons that synthesize modulatory peptides, and the muscles innervated by these neurons. This may prove to be an advantageous preparation to study cotransmission because these neurons have discrete identified targets and express a variety of peptide cotransmitters. These results should prove useful in directing future physiological experiments.

\section{References}

Adams ME, O'Shea M (1983) Peptide cotransmitters at a neuromuscular junction. Science 221:286-289.

Bishop CA, Wine JJ, O'Shea M (1984) Neuropeptide proctolin in postural motor neurons of the crayfish. J Neurosci 4:2001-2009.

Bishop CA, Wine JJ, Nagy F, O'Shea MR (1987) Physiological consequences of a peptide cotransmitter in a crayfish nerve-muscle preparation. J Neurosci 7:1769-1779.

Calabrese RL (1989) Modulation of muscle and neuromuscular junctions in invertebrates. Semin Neurosci 1:25-34.

Ch'ng JL, Christofides ND, Anand P, Gibson SJ, Allen YS, Su HC, Tatemolo K, Morrison JFB, Polak JM, Bloom SR (1985) Distribution of galanin immunoreactivity in the central nervous system and the responses of galanin-containing neuronal pathways to injury. Neuroscience 16:343-354.

Church PJ, Cohen KP, Scott ML, Kirk MD (1991) Peptidergic motoneurons in the buccal ganglia of Aplysia californica: immunocytochemical, morphological, and physiological characterizations. J Comp Physiol, in press.

Cohen JL, Weiss KR, Kupfermann I (1978) Motor control of buccal muscles in Aplysia. J Neurophysiol 41:157-180.

Cropper EC, Lloyd PE, Reed W, Tenenbaum R, Kupfermann I, Weiss KR (1987a) Multiple neuropeptides in cholinergic motor neurons of Aplysia: evidence for modulation intrinsic to the motor circuit. Proc Natl Acad Sci USA 84:3486-3490.

Cropper EC, Tenenbaum R, Gawinowicz Kolks MA, Kupfermann I, Weiss KR (1987b) Myomodulin: a bioactive neuropeptide present in an identified cholinergic buccal motor neuron of Aplysia. Proc Natl Acad Sci USA 84:5483-5486.

Cropper EC, Miller MW, Tenenbaum R, Gawinowicz Kolks MA, Kupfermann I, Weiss KR (1988) Structure and action of buccalin: a modulatory neuropeptide localized to an identified small cardioactive peptide-containing cholinergic motor neuron of Aplysia californica. Proc Natl Acad Sci USA 85:6177-6181.

Cropper EC, Price D, Tenenbaum R, Kupfermann I, Weiss KR (1990) Release of peptide cotransmitters from cholinergic neuron under physiological conditions. Proc Natl Acad Sci USA 87:933-937.

Fiore L, Geppetti L (1980) Neural control of buccal mass activity in Aplysia. In: Advances in physiological sciences, Vol 23, Neurobiology of invertebrates (Salanki J, ed), pp 201-223. Budapest: Pergamon.

Fisher JM, Sossin W, Newcomb R, Scheller RH (1988) Multiple neuropeptides derived from a common precursor are differentially packaged and transported. Cell 54:813-822.

Gardner D (1971) Bilateral symmetry and interneuronal organization in the buccal ganglia of Aplysia. Science 173:550-553.

Gardner D, Kandel ER (1977) Physiological and kinetic properties of cholinergic receptors activated by multiaction interneurons in buccal ganglia of Aplysia. J Neurophysiol 40:333-348.

Gibson SJ, Polak JM, Bloom SR, Sabate IM, Muldberry PM, Ghatel MA, McGregor GP, Morrison JFB, Kelly JS, Evans RM, Rosenfeld MG (1984) Calcitonin gene-related peptide immunoreactivity in the spinal cord of man and eight other species. J Neurosci 4:31013111

Howells HH (1942) The structure and function of the alimentary canal of Aplysia punctata. Q J Microsc Sci 83:357-397.

Kreiner T, Sossin W, Scheller RH (1986) Localization of Aplysia neurosecretory peptides to multiple populations of dense core vesicles. J Cell Biol 102:769-782.

Kuhlman JR, Li C, Calabrese RL (1985) FMRF-amide-like substances in the leech. I. Immunocytological localization. J Neurosci 5:23012309.

Kupfermann 1 (1974) Feeding behavior in Aplysia: a simple system for the study of motivation. Behav Biol 10:1-26.

Kupfermann I, Cropper EC, Miller MW, Alevizos A, Tenenbaum R, Weiss KR (1988) Buccalin: distribution of immunoreactivity in the Aplysia nervous system and biochemical localization to motor neuron B16. Soc Neurosci Abstr 14:177.

Lloyd PE (1978) Distribution and molecular characteristics of cardioactive peptides in the snail, Helix aspersa. J Comp Physiol 128 269-276.

Lloyd, PE (1986) The small cardioactive peptides: a class of modulatory neuropeptides in Aplysia. Trends Neurosci 9:428-431.

Lloyd PE (1988) Fast axonal transport of modulatory neuropeptides from central ganglia to components of the feeding system in Aplysia. J Neurosci 8:3507-3514.

Lloyd PE, Kupfermann I, Weiss KR (1984) Evidence for parallel actions of a molluscan peptide $\left(\mathrm{SCP}_{\mathrm{B}}\right)$ and serotonin in mediating arousal in Aplysia. Proc Natl Acad Sci USA 81:2934-2937.

Lloyd PE, Mahon AC, Kupfermann I, Cohen JL, Scheller RH, Weiss KR (1985) Biochemical and immunocytological localization of molluscan small cardioactive peptides (SCPs) in the nervous system of Aplysia californica. J Neurosci 5:1851-1861.

Lloyd PE, Schacher S, Kupfermann I, Weiss KR (1986) Calciumdependent release of neuropeptides during intracellular stimulation of single identified Aplysia neurons in culture. Proc Natl Acad Sci USA 83:9794-9798.

Lloyd PE, Kupfermann I, Weiss KR (1987a) The sequence of small cardioactive peptide $A$ : a second member of a class of neuropeptides in Aplysia. Peptides 8:179-184.

Lloyd PE, Frankfurt M, Stevens P, Kupfermann I, Weiss KR (1987b) Biochemical and immunocytological localization of the neuropeptides FMRFamide, $\mathrm{SCP}_{\mathrm{A}}$, and $\mathrm{SCP}_{\mathrm{B}}$, to neurons involved in the regulation of feeding in Aplysia. J Neurosci 7:1123-1132.

Lloyd PE, Kupfermann I, Weiss KR (1988) Central peptidergic neurons regulate gut motility in Aplysia. J Neurophysiol 59:1613-1626.

Lotshaw DP, Lloyd PE (1990) Peptidergic and serotonergic facilitation of a neuromuscular synapse in Aplysia. Brain Res 526:81-94.

Mahon AC, Lloyd PE, Weiss KR, Kupfermann I, Scheller RH (1985) The small cardioactive peptides A and B of Aplysia are derived from a common precursor molecule. Proc Natl Acad Sci USA 82:39253929.

Miller MW, Kupfermann I, Weiss KR (1988) Characterization of the 
$\mathrm{SCP}_{\mathrm{B}}$ immunoreactive cells in the buccal ganglion of Aplysia. Soc Neurosci Abstr 14:536.

Miller MW, Cropper EC, Eisinger K, Villim F, Tenenbaum R, Beushausen S, Brosius J, Kupfermann I, Weiss KR (1989) The buccalin neuropeptide family in Aplysia: purification of buccalin $\mathrm{C}$ and sequence of additional peptides predicted by a cDNA clone. Soc Neurosci Abstr 15:665.

Morris HR, Panico M, Karplus A, Lloyd PE, Riniker B (1982) Elucidation by FAB-MS of the structure of a new cardioactive peptide from Aplysia. Nature 300:643-645.

Mulle C, Benoit P, Pinset C, Roa M, Changeux J-P (1988) Calcitonin gene-related peptide enhances the rate of desensitization of the nicotinic acetylcholine receptor in culture mouse muscle cells. Proc Natl Acad Sci USA 85:5728-5732.

Nagahama T, Takata $M$ (1990) Innervation of buccal muscles by multifunctional MA1 neurons in Aplysia kurodai. J Comp Physiol A 167:1-10.

Ncw HV, Mudgc AW (1986) Calcitonin gene-related peptide regulates muscle acetylcholine receptor synthesis. Nature 323:809-811.

Ono JK (1986) Localization and identification of neurons with cholecystokinin and gastrin-like immunoreactivity in wholemounts of Aplysia ganglia. Neuroscience 18:957-974.

Ono JK, McCaman RE (1980) Identification of additional histaminergic neurons in Aplysia: improvement of single cell isolation techniques for in tandem physiological and chemical studies. Neuroscience 5:835-840.

Ono JK, McCaman RE (1984) Immunocytological localization and direct assays of serotonin-containing neurons in Aplysia. Neuroscience 11:549-560.

O'Shea M, Schaffer M (1985) Neuropeptide function: the invertebrate contribution. Annu Rev Neurosci 8:171-198.

Price DA, Grecnberg MJ (1977) Structure of a molluscan cardioexcitatory neuropeptide. Science 197:670-671.

Reed W, Weiss KR, Lloyd PE, Kupfermann I, Chen M, Bailey CH (1988) Association of neuroactive peptides with the protein secretory pathway in identified neurons of Aplysia californica: immunolocaliza- tion of $\mathrm{SCP}_{A}$ and $\mathrm{SCP}_{\mathrm{B}}$ to the contents of dense-core vesicles and the Trans face of the Golgi apparatus. J Comp Neurol 272:358-369.

Richmond JE, Bulloch AGM, Lukowiak K (1986) Peptidergic modulation of a neuromuscular junction in Aplysia: bioactivity and immunocytochemistry. Brain Res 370:159-164.

Rosen SC, Weiss KR, Cohen JL, Kupfermann I (1982) Interganglionic cerebral-buccal mechanoafferents of Aplysia: receptive fields and synaptic connections to different classes of neurons involved in feeding behavior. J Neurophysiol 48:271-288.

Schwartz JH, Shkolnik LJ (1981) The giant serotonergic neuron of Aplysia: a multi-targeted nerve cell. J Neurosci 1:606-619.

Schwarz TL, Lee GMH, Siwicki KK, Standaert DG, Kravitz EA (1984) Proctolin in the lobster: the distribution, release, and characterization of a likely neurohormone. J Neurosci 4:1300-1311.

Susswein A, Weiss KR, Kupfermann I (1978) The effects of food arousal on the latency of biting in Aplysia. J Comp Physiol 123:3141.

Taussig R, Scheller RH (1986) The Aplysia FMRFamide gene encodes sequences related to mammalian brain peptides. DNA 5:453-461.

Villim FS, Cropper EC, Alevizos A, Tenenbaum R, Kupfermann I, Weiss KR (1989) Structure determination and cellular localization of a novel myomodulin related octapeptide in Aplysia. Soc Neurosci Abstr 15:665.

Weiss KR, Lloyd PE, Cropper EC, Frankfurt M, Kupfermann I (1986) FMRFamide is present in the ARC muscle of Aplysia and depresses its contractions. Soc Neurosci Abstr 12:946.

Weiss KR, Cropper EC, Tenenbaum R, Villim FS, Kupfermann I (1988) Action and structure of parabuccalin - a novel neuropeptide localized to cholinergic motor neurons B 15 and B 6 of Aplysia. Soc Neurosci Abstr 14:177.

Whim MD, Lloyd PE (1989) Frequency-dependent release of peptide cotransmitters from identified cholinergic motor neurons in Aplysia. Proc Natl Acad Sci USA 86:9034-9038.

Whim MD, Lloyd PE (1990) Neuropeptide cotransmitters released from an identified cholinergic motor neuron modulate neuromuscular efficacy in Aplysia. J Neurosci 10:3313-3322. 